\title{
PERSPECTIVA
}

\section{Conexão Escola-Mundo: espaços inovadores para a formação cidadã}

A proposta do dossiê "Educação, Direitos Humanos e Ética Hacker " trata do marco teórico que fundamenta o projeto de pesquisa "Conexão Escola-Mundo: espaços inovadores de formação cidadã", um projeto de cooperação nacional e internacional financiado pelo CNPq e apoiado pela CAPES, FAPESC, FAPESB, UFBA e UFSC. Esta pesquisa foi coordenada pelos professores Nelson Pretto, da Universidade Federal da Bahia, e Andrea Lapa, da Universidade Federal de Santa Catarina e contou com o envolvimento de professores e alunos dessas universidades e das escolas da educação básica parceiras, CEEPIA - Centro Estadual de Educação Profissional Isaías Alves, em Salvador, e Colégio de Aplicação/UFSC, em Florianópolis. Participaram também as equipes do Laboratório de Mídias Interativas da Universidade Barcelona (Espanha) e do Instituto de Desenvolvimento e Direitos Humanos (IDDH), assim como pesquisadores da Universidade de Joinville (UNIVILLE), da Universidade Federal do Rio Grande do Sul, Universidade Federal do Espírito Santo, do Instituto Federal de São Paulo (Campus Capivari) e da Università degli Studi della Tuscia (Itália).

O projeto aconteceu entre os anos de 2018 a 2021, levado a cabo por professores e estudantes da pós-graduação, graduação e educação básica envolvidos na pesquisa participativa e ativista a partir de dois grupos de pesquisa brasileiros: o GEC (Grupo de Pesquisa Educação, Comunicação e Tecnologias/UFBA) e o Comunic (Mídia-Educação e Comunicação Educacional/UFSC). Enquanto estivemos comprometidos com a criação e execução, coletivas e colaborativas, de planos de ação nas duas escolas da educação básica (CEEPIA e Colégio de Aplicação), realizamos a reflexão e diversas investigações nestes dois contextos empíricos.

O projeto Conexão Escola-Mundo partiu de uma inquietação que nos afetava diretamente, uma vez que, desde a expansão da internet, testemunhamos a erosão dos limites tradicionais das mídias clássicas e o aparecimento de práticas colaborativas que surgiam em torno de um novo ecossistema midiático chamado cultura digital. $\mathrm{O}$ debate já exaurido sobre a inevitabilidade do avanço tecnológico, devido à penetrabilidade das tecnologias na vida cotidiana, tampouco está contribuindo para o tratamento da 
questão, pois é comum a adoção de um olhar binário para a problemática o que é, no fundo, reducionista. Enquanto alguns entusiastas celebram o poder da tecnologia de renovar a vida política, cultural e cívica, de liberar populações oprimidas, incluir os explorados e marginalizados (RHEINGOLD, 1993; SHIRKY, 2015; BENKLER, 2006, 2015), pensadores mais céticos denunciam a trivialização da política e da cultura, a desumanização das relações e o esfacelamento do tecido social (KEEN, 2007; TURKLE, 2011). Para evitar a condenação de tecnófobos e a celebração ingênua dos tecnófilos, a cultura digital necessita ser vista em toda a sua ambivalência, em uma abordagem desconfiada que navegue com criticidade em toda a região entre esses pólos.

Uma melhor compreensão da problemática passa necessariamente por reconhecer a não neutralidade das tecnologias e a ameaça, sempre presente, de outra forma de colonização social levada a cabo por uma nova configuração da indústria cultural (ADORNO; HORKHEIMER, 1985; FEENBERG, 2002). Mas, além deste passo, deve transcender a leitura crítica das condições restritivas dadas pelos meios técnicos e buscar brechas, o devir do possível. Destacamos como um espaço de possibilidade a valorização da comunicação no desenvolvimento de novas formas de associação e solidariedade para o surgimento de uma sociedade livre (KELLNER, 1989) e, na sua esteira, a premente formação crítica de sujeitos. Porque o problema, e tampouco a solução, está na tecnologia em si. A potencialidade de subversão da lógica programada (MACHADO, 2002) estaria no controle humano das Tecnologias de Informação e Comunicação (TIC) e o seu maior obstáculo ainda tem sido o nosso fracasso em inventar instituições apropriadas para produzir esta alternativa (FEENBERG, 2002).

A Web como um espaço de interação entre seus usuários expandiu a possibilidade de aparecimento dos indivíduos no espaço público e permitiu o incremento da pluralidade. Apesar da importante discussão sobre o acesso aos meios técnicos (dos equipamentos às redes e conexões) e da inclusão de todos nas relações de poder que definem o acesso à difusão (quem prioriza o que aparece, quem define o que se lê), enfatizamos o necessário empoderamento dos sujeitos incluídos na cultura digital como estratégia imprescindível para que estes espaços plurais se configurem também como espaços democráticos de aproximação e de encontro com o outro.

O empoderamento dos sujeitos capazes de se apropriarem crítica e criativamente do ciberespaço significa ir além da recepção desconfiada dos meios, transcendendo-o e incorporando uma papel ativo, de autor e produtor (portanto 
ativista!), que é a base fundamental para estarem presentes na cultura digital como sujeitos plenos, em ação emancipadora e transformadora na sociedade. Por isso, defendemos que o acesso aos artefatos tecnológicos, à conexão em redes digitais e aos conteúdos e pessoas desta rede deva ser irrestrito e total. Os recursos tecnológicos hoje já promovem potencialmente a descentralização das produções e decisões, viabilizando um uso mais cooperativo e integrado. A livre circulação de informação e conhecimento, aliada a práticas colaborativas de produção e coprodução abertas trazem um novo modo de vida e de relação social, que afeta e contagia todos os setores da vida cotidiana das pessoas.

Por este motivo nos voltamos para a educação, pois o desafio parece estar em explorar a latência destes sujeitos imersos em um novo contexto - do tempo e do espaço da mediação tecnológica -, onde as relações sociais acontecem de maneira distinta e o cultivo do homem, portanto, a cultura, se transforma.

Diante deste cenário, torna-se insuficiente a formulação mais tradicional da educação que se confina na visão de escolarização e esta, por sua vez, na aquisição de conhecimentos e habilidades. Como apontado por Martín-Barbero (2014), o novo estatuto da mutação sociotécnica que hoje desafia o sistema educativo é o surgimento de outra sociabilidade e outra sensibilidade que as tecnologias ajudam a engendrar na sociedade contemporânea. Esta outra sociabilidade balança os muros da escola e nos move a pensar que a escola na cultura digital significa um espaço híbrido que engloba o dentro e fora. A conexão escola-mundo se torna um particular e especial espaço de vivência e produção do conhecimento em processos sociais organizados em redes de colaboração.

A aposta é de que a internet pode ajudar a vitalizar a cultura cívica em esferas públicas informais e que estas podem ter um papel modesto, porém relevante, no que Peter Dahlgren (2004) chamou de pré-condições para uma identidade cidadã e compromisso em esferas públicas promovidas por novas formas de participação online. Porém, este potencial pode vir a se expressar se a atuação em rede for exercida criticamente, isto é, se os sujeitos que habitam e produzem esta cultura digital forem capazes de fazer o que Milton Santos chamou de uma outra globalização: reconhecer as determinações postas pelas tecnologias digitais e ainda assim buscar formas alternativas de apropriação que atendam objetivos mais humanos e sociais (LAPA, A., 2013).

Diante do atual contexto da imersão na cultura digital, enfrentamos dois desafios principais. O primeiro está relacionado à aceleração e à ampliação das formas 
de comunicação que poderiam significar uma maior condição de diálogo plural, de convívio da diferença e de encontro com o outro, mas que, de fato, têm se mostrado espaço promotor da intolerância, do preconceito, do discurso de ódio, da violência. As redes digitais de comunicação vêm propiciando às pessoas a capacidade de acessar informações e recursos, articular suas próprias histórias, influenciar os problemas políticos que lhe dizem respeito, ampliar a confiança e a autonomia para fazer escolhas livres e significativas (FORTUNATI, 2014).

Por outro lado, nunca se assistiu tão livremente à expressão do ódio. O fomento à segregação, ao racismo e à discriminação, por exemplo, chegam a tensionar o limite dos direitos humanos e repercutir fora da web. Concordamos com Déborah Antunes e Antonio Zuin (2008) sobre a educação ser o caminho para a superação da barbárie. No entanto, em sua forma atual, a educação reflete e espelha estes modelos competitivos e excludentes das redes sociais e, ao contrário do esperado, ajuda a explicitar e reforçar, cada vez mais, as relações de heteronomia estabelecidas no mundo para além dos muros escolares. Nesse sentido, as práticas de violência nas escolas devem ser compreendidas por meio da análise social, nas formas como se organizam as forças objetivas da sociedade e como elas se materializam e se calcificam nos sujeitos que se desenvolvem nesse meio.

O verdadeiro salto para a superação da barbárie (o não reconhecimento do outro e a consequente tentativa de sua exclusão) se dá através de uma educação que proponha a aceitação da alteridade e a necessária convivência democrática da pluralidade. O caminho para educadores e professores parece ser o de criar espaços que sejam promotores do encontro com o outro. De identificar, na mediação tecnológica, formas de apropriação que subvertam a tendência à polarização e à intolerância em direção a um uso que incentive o encontro e o diálogo com o outro. O outro entendido aqui como todo aquele que é diferente de mim e que, no seu encontro comigo, no exercício da identidade e diferença que promove este encontro, possa tornar-me conhecedor de um mundo diverso e também inclusivo.

Destaca-se, portanto, a relevância de uma educação para os direitos humanos que, segundo o Programa Mundial de Educação em Direitos Humanos, é definida como um processo de aprendizagem, formação e informação que implica a promoção de uma cultura universal dos Direitos Humanos. Ela envolve, além da aprendizagem de seus conteúdos (que direitos são esses e seus mecanismos de proteção), “a aquisição ou fortalecimento de habilidades necessárias para aplicar esses direitos de forma prática na vida diária” (BRASIL, 2009, p. 25). 
Foi a partir dessas premissas que esse área se vinculou ao nosso campo de estudos e debate sobre a integração de tecnologias digitais de informação e comunicação (TDIC) à educação, uma vez que ele está indelevelmente associado à ideia de transformação social e tem ampla afinidade com o caráter emancipador e democrático das práticas educativas na cultura digital que defendemos.

Para que essa possibilidade se concretize, porém, outras “educações” são necessárias (PRETTO; PINTO, 2006; PRETTO, 2011), distintas das que vêm sendo realizadas pelo atual sistema de ensino, com ou sem TDIC. Pensamos na necessidade de maior foco no processo do que no produto, na criação e vivência de espaços de possibilidade de uma formação democrática e cidadã, que contemple a aproximação e o encontro com o outro. Por esta razão, para o desafio do crescimento da intolerância e da violência e sua amplificação através de novas formas de comunicação, destacamos como alternativa a educação para os direitos humanos através da imersão na cultura digital, em espaços híbridos de conexão online-offline em uma perspectiva hacker. Uma perspectiva baseada no ideal daqueles jovens estudantes (particularmente no MIT/Boston) que estavam interessados no desenvolvimento tecnológico e nas mudanças do mundo. $\mathrm{O}$ que fizeram foi desenhar programas e máquinas a partir de uma nova linguagem que começava a ser concebida e que tem como metodologia resolver os problemas de forma compartilhada. E cada solução alcançada circulava para ser objeto de crítica de novos colaboradores, delineando-se um código de ética dos primeiros hackers (LEVY, 2012; HIMANEN, 2001).

Ao mesmo tempo, essas outras educações se constituem a partir da constatação de que as TDIC propiciam outras e novas formas de comunicação (que são um relevante espaço atual de convívio de crianças, jovens e adultos), e, assim, constituem um terreno fértil para a transformação. A pergunta que nos implica é se haveria instrumentos e métodos capazes de permitir que estes espaços (híbridos) de comunicação em rede fossem apropriados dentro da escola em uma perspectiva de encontro com o outro, de reconhecimento, convívio e enaltecimento da diferença, de respeito à pluralidade e de diálogo das diferenças em busca de um mundo comum possível. A busca dessa alternativa tornou-se um espaço de ação vital para a construção de uma nova escola na cultura digital.

Com isso, chegamos ao segundo desafio enfrentado em nossa proposta, que está na inclusão na cultura digital através de uma apropriação crítica e criativa de TDIC. Pesquisas anteriores nos grupos de pesquisa GEC e Comunic (Lapa e Espíndola, 2019; Lapa e Lacerda, 2018; Pretto, 217; Quartiero; Bonilla e Fantim, 2015) identificaram 
alguns problemas, como a) o distanciamento dos profissionais das escolas dos processos de tomada de decisão acerca de políticas e propostas a serem executadas em suas unidades escolares; b) a constituição de um contexto comunicativo e de uma nova cultura de produção e circulação de conhecimento, em função da crescente adesão das tecnologias digitais de informação e comunicação no cotidiano da população; c) a necessidade de inserção da perspectiva de formação crítica e orientada aos direitos humanos às políticas públicas de educação no país; d) a ausência de políticas públicas integradas e integradoras das diversas áreas do conhecimento não possibilitando, com isso o enfrentamento dos desafios contemporâneos.

Percebemos que o enfrentamento dos grandes desafios postos para a educação a partir da integração de TDIC - e para a escola em particular - demanda um olhar multifacetado para os diversos componentes que povoam o ecossistema educacional. As redes digitais de informação e comunicação "derrubaram” os muros da escola, pelo menos potencialmente. Os currículos, a formação dos professores, os materiais educacionais em seus diversos suportes, a arquitetura escolar, tudo está em questão. Porém, as políticas públicas que vêm sendo executadas ao longo dos anos continuam a deixar o sistema educacional em um nível de estagnação que não apresenta saída para os enormes problemas nacionais. Desta forma, os profissionais que estão mais próximos desta realidade terminam sendo alijados de iniciativas de gestão e de criação de estratégias para enfrentamento dos desafios identificados. Este limite foi evidenciado com a crise planetária da pandemia de Sars-Covid-19, que não mais acobertou as diversas tarefas não cumpridas na integração das TDIC às escolas, em especial as públicas.

O sociólogo Muniz Sodré (2012) já assinalava que os resultados só serão alcançados a partir de um pacto nacional sobre a educação, por meio de consenso estabelecido não somente no círculo técnico de especialistas, mas na esfera pública em um projeto político coletivo no qual a classe política fizesse eco das aspirações coletivas de uma forma mais democrática. O cenário nas escolas conduz a um paradigma de rara integração de TDIC no ensino, ou, quando acontece está, em grande parte, em fases iniciais de familiarização, adoção e adaptação das TDIC em práticas tradicionais de ensino e poucas vezes em apropriação criativa e inventiva (ESPÍNDOLA, 2010).

Práticas alternativas podem ser encontradas em exemplos que vêm sendo tecidos a partir do ecossistema de troca e produção coletiva de conhecimento que acontece na internet. Novas práticas ligadas à noção do Aberto (openness: ciência 
aberta, acesso aberto, dados abertos, recursos educacionais abertos) vão conquistando espaço e passam a se fazer presentes em diversas áreas, mas com pouca intensidade na escola e na formação dos professores, fazendo com que haja um grande descompasso da educação com o contexto contemporâneo. É essa perspectiva de abertura e do livre acesso aos conhecimentos, que temos visto crescer ampliando assim o importante movimento da Ciência Aberta e Cidadã (ALBAGLI; MACIEL; ABDO 2015). São significativos os exemplos de projetos vitoriosos nessa linha evidenciando o quanto a produção social transforma o mercado e a liberdade (BENKLER, 2015).

A tendência de abertura de práticas importantes como a mencionadas, reafirmam um movimento de compreensão da sociedade cujo viés organizador está centrado no conhecimento, e principalmente o conhecimento em rede. É nesse sentido que Bartolomé Pina (2011), afirma que a chave da preparação de cidadãos competentes na Sociedade de Aprendizagem está em ensiná-los a serem capazes de analisar uma situação e encontrar os elementos-chave, a fazer as perguntas não resolvidas que permitirão compreender e avançar.

Este intento demanda pesquisa acadêmica, atuação ativista dos próprios pesquisadores, e forte envolvimento da comunidade escolar, desde o início de todos os processos, e de forma permanente. Neste contexto, o papel da escola muda, porque, se por um lado está mais evidente que não é (nem nunca poderia ser) o espaço exclusivo para a aprendizagem e a produção do conhecimento, por outro, desempenha um importante papel na sua participação e referência nos variados espaços públicos educativos da sociedade contemporânea. Dizemos mais: é um espaço privilegiado para essa formação e atuação das juventudes, aqui compreendidas sempre numa perspectiva plural, como insiste Juarez Dayrell (2007).

E essas juventudes, para que se re-encantem com a escola, precisam ver sentido na mesma. Para nós, um dos caminhos, certamente não o único, mas de grande importância, é fortalecer a dimensão produção de culturas e conhecimento em detrimento de uma lógica centrada no consumo de informações. E aqui, os movimentos hackers podem muito a nos servir como inspiração para a construção do que denominamos de perspectiva plural da educação, com o fortalecimento de professores e alunos como fazedores do seu próprio tempo.

Explicando um pouco mais em detalhe. A ideia de produção colaborativa e compartilhada ganhou destaque no final do século passado a partir do desenvolvimento da computação e com os movimentos do software livre e do código aberto. Eram os tais movimentos hackers, que surgem no início do desenvolvimento da ciência da 
computação: aqueles primeiros jovens estudantes interessados no desenvolvimento tecnológico e nas mudanças do mundo, que começaram a desenhar programas e máquinas a partir de uma nova linguagem que começava a ser concebida. Desta forma, nasceu a linguagem binária, que possibilita o digital. Foram esses jovens, reunidos nas garagens ou laboratórios das universidades americanas, particularmente no MIT (Instituto de Tecnologia de Massachusetts), com ou sem os seus professores, que começaram a desenvolver os primeiros computadores pessoais. Boa parte desses movimentos tinham como princípio uma intensa lógica de compartilhamento, inerente à própria cultura daqueles que passaram a ser conhecidos como hackers. O processo de produção desses novos aparatos tinha como metodologia resolver os problemas surgidos em cada um dos projetos de forma compartilhada. E cada solução alcançada circulava para ser objeto de crítica de novos colaboradores, conforme já desenvolvemos em artigo anterior (PRETTO, 2010). Essa turma jovem estava organizada em torno de clubes juvenis e reuniam-se para resolver os problemas tecnológicos que iam surgindo e, com isso, criavam e desenvolviam novos protótipos. Enquanto estes jovens inovavam tecnologicamente, criavam ao mesmo tempo o que Steven Levy denominou de código de ética dos primeiros hackers (LEVY, 2012). Para o hacker, o acesso aos computadores e a qualquer coisa que possa ensinar algo sobre o funcionamento do mundo, bem como a própria informação, deve ser irrestrito e total. Por outro lado, as criações dos hackers devem estar sempre disponíveis para serem aperfeiçoadas, sendo importante não confiar nos argumentos de autoridade e, ao mesmo tempo, promover sempre a descentralização das produções e decisões. Para os hackers, de fato, os sistemas descentralizados funcionam muito melhor do que os centralizados e burocratizados. Um hacker tem participação ativa no seu grupo social: produz conteúdos e os fazem circular imediatamente para que possam ser testados e aperfeiçoados por todos. Eles reconhecem o esforço do outro e dão créditos aos desenvolvedores anteriores. Um hacker não deve ser julgado com base em qualificações, idade, raça ou posição, mas segundo a sua obra. Para o movimento hacker, é importante sempre inovar, buscando constantemente melhorar o que foi produzido.

Este modelo de criação coletiva tem nos levado, enquanto pesquisadores, a buscar compreender mais os processos de funcionamento dessas experiências libertadoras, que fogem ao enquadramento reducionista. Temos como pressuposto que este modelo de trabalho colaborativo enriquece processos de aprendizado e, ao ignorar este universo para pesquisa, o campo da educação desperdiça a potencialidade deste 
movimento em tecer contribuições aos modelos educativos que podem, segundo a visão aqui defendida, colocar a escola em consonância com as formas de produção e troca de conhecimento do século XXI.

A ética hacker, trazida à educação e à pesquisa em educação, significa a valorização da autonomia, protagonismo, empoderamento, autoria e produção coletiva e colaborativa. A educação hacker pressupõe uma prática colaborativa que traz em si o acesso livre e aberto ao conhecimento e aos produtos do conhecimento, que anuncia um processo de fazer coletivo e de ativismo (BONILLA; PRETTO, 2015).

Portanto, este dossiê trata de pensar e propor outros paradigmas para a educação, fundamentado na inter-relação entre educação em direitos humanos e educação hacker, articulando e colocando em diálogo contribuições teóricas e de pesquisa que integram este ambiente sinérgico de concepção deste paradigma para educações outras, que possam, talvez, melhor responder aos desafios contemporâneos. Este marco teórico e metodológico orientou as ações e pesquisas do projeto Conexão Escola-Mundo, mas, sendo fiel aos acontecimentos e estes às suas premissas iniciais, ele foi se constituindo aos poucos, em sentido e prática, na relação dos participantes e envolvidos, na ação reflexiva e ativista nas escolas e nas universidades, nos espaços colaborativos criados como oportunidades de produção de conhecimento no processo de ação coletiva e ativista do projeto.

Dessa forma, o dossiê "Educação, Direitos Humanos e Ética Hacker" foi elaborado com a intenção de contribuir para a reflexão e a ação na área da Educação em um dos seus grandes desafios que se refere à formação crítica e criativa do sujeito para a sua inclusão e empoderamento na cultura digital. Ao reunir em uma publicação uma rede de investigadores formada (e ampliada) para o projeto de pesquisa, esta equipe multidisciplinar compartilha suas bagagens específicas de pesquisa que aportam para a investigação em colaboração, tais como: escola hacker/educação hacker; educação para a cidadania na cultura digital; educação em direitos humanos; formação de professores; novos contextos de aprendizagem; políticas públicas em educação na era digital; software livre; capitalismo de plataforma, entre outros.

O conjunto de artigos deste dossiê se constitui numa miríade de olhares sobre essa temática que é, por si só, multifacetada. Nossas abordagens se entrecruzam ao longo de cada um dos textos, de tal forma que a ordem aqui apresentada representa esse movimento, meio caótico, ora sendo pesquisa, ora intervenção, ora proposta metodológica, ora pressuposto para a pesquisa, ora os seus resultados, de tal forma que é o conjunto que possibilita a construção do que estamos denominando de uma 
metodologia de intervenção com/na escola para a formação em direitos humanos dentro da perspectiva da educação hacker.

Começamos o nosso debate pelo artigo de Isabel Colucci Coelho e Andrea Brandão Lapa: "Escola e Internet: espaços de formação para a cidadania". As autoras, indignadas com a promessa não cumprida de ampliação democrática trazida pela internet e demais tecnologias digitais de comunicação em rede, nos provocam a refletir e enunciar os desafios postos pela integração de tecnologias à educação. Para procurar espaços possíveis de formação crítica de cidadãos no contexto da cultura digital, tema de estudo e investigação no grupo de pesquisa Comunic/UFSC, elas nos trazem a proposta de um paradigma alternativo de educação baseado na educação em direitos humanos em uma escola conectada com o mundo. Como conteúdo e como prática para uma educação democrática e emancipadora.

Tel Amiel, Thiago Pezzo, Leonardo Ribeiro da Cruz e Luisa Antunes Oliveira nos provocam a pensar sobre a crescente parceria das instituições públicas com grandes empresas de tecnologias para os serviços digitais para a educação no artigo "Os modos de adesão e a abrangência do capitalismo de vigilância na educação brasileira". A partir da análise dos acordos firmados entre eles, os autores problematizam o tratamento de dados privados estratégicos e sensíveis de profissionais e estudantes das instituições e as consequências destas escolhas para a autonomia destas redes de ensino e instituições.

Na sequência, o artigo “A Educação em Direitos Humanos na América Latina" nos convida a um diálogo intercultural entre experiências de educação em direitos humanos em diferentes países latinoamericanos, como Uruguai, Chile, Argentina e Brasil. Importantes intelectuais e ativistas de seus países que são, Fernanda Brandão Lapa, Fernando Alberto Willat Koch, Isabel Plaza Lizama e Matias Pascual Penhos, analisam e colocam em relação políticas públicas e ações de seus respectivos países, buscando convergências que apontem parâmetros comuns que poderiam ser assumidos como bases mínimas para alcançar o pleno desenvolvimento humano que almejamos em nosso continente.

O desafio posto pela educação em direitos humanos no momento contemporâneo se refere à formação para a cidadania no contexto da cultura digital. Resvala, necessariamente, no papel das tecnologias de informação e comunicação na sociedade e, em especial, na sua presença e integração na educação. Neste sentido, no artigo intitulado "Educação na cultura digital: novas ambiências de aprendizagem e implicações para a formação de professores", António Bartolomé-Pina, Marina 
Bazzo de Espíndola, Ian Narciso Rocha Lima e André Ary Leonel problematizam as questões centrais do pensamento educativo na contemporaneidade, tecendo uma reflexão sobre os limites e as possibilidades pedagógicas das TDIC na constituição de novas ambiências de aprendizagem na cultura digital. Como questão central deste ensaio teórico, refletem sobre as implicações deste contexto para a formação de professores em diálogo com as vozes da equipe de professoras de uma escola parceira do projeto. Por se tratar de um desafio que exige novos conteúdos e novos caminhos metodológicos que incentivem a autoria, o protagonismo, a produção coletiva, a colaboração e a pesquisa, os autores apresentam, por fim, o desenho de uma proposta formativa baseada na pesquisa e desenvolvimento coletivo de ações educativas experienciada no primeiro ciclo do Projeto Conexão Escola-Mundo.

$O$ artigo "Cultura hacker e educação: percepções dos hackers sobre a vivência de elementos de sua cultura nas escolas" apresenta uma investigação feita com hackers de distintos movimentos e países sobre como consideram a presença da cultura hacker nas escolas, parte de uma tese de doutorado defendida na Universidade Autónoma de Barcelona. Apontando aspectos relevantes para a educação hacker, Alexandre Aguado e Isabel Alvarez Canovas analisam significados e relações entre a pedagogia crítica e as características da cultura hacker que foram apontadas pelos hackers como realidade e, também, como possibilidade.

Daniel Silva Pinheiro, Karina Moreira Menezes e Salete de Fátima Noro Cordeiro vão nos auxiliar a ver a possibilidade da educação hacker na prática quando apresentam e analisam experiências de prática aberta e colaborativa desenvolvidas, uma dentro do escopo da ação do Projeto Conexão Escola-Mundo na escola e outra na sua relação com uma componente curricular do curso de licenciatura na universidade. No artigo "Criar de um jeito hacker: experiências na/com a escola e a universidade", eles nos instigam a refletir sobre a potencialidade do jeito hacker de ser na prática da estrutura dos sistemas de ensino, seja escolar ou universitário.

Por último, Carla Aragão, Karla Brunet e Nelson Pretto nos levam para o chão da escola e para a prática, para vislumbrarmos como, afinal, poderia se constituir essa educação hacker. Os autores propõem no artigo "Hackear a educação por dentro" formas de operar transformações na escola a partir da perspectiva ativista de empoderamento, autoria e produção colaborativa da ética hacker. Fazem a proposta da escola com um jeito hacker de ser, ancorados em muitos anos de pesquisa e também de experimentação nas escolas públicas a partir do grupo de pesquisa GEC/UFBA. 
Esperamos que essa publicação contribua para a área da Educação ao abordar outros paradigmas para a educação aberta e conectada com o mundo a partir da inclusão crítica e criativa dos sujeitos na cultura digital. Apostamos que esses nossos olhares, múltiplos, em rede, produzidos também eles desde o nascedouro de forma colaborativa, possas vir a se constituir em elementos que possibilitem a construção de um ecossistema favorável à formação de cidadãos para os direitos humanos na cultura digital, e que possa ser incorporado às práticas pedagógicas nos contextos educativos formais e não formais, assim como se constituir em elementos para um profundo repensar das políticas públicas brasileira em educação, sempre numa perspectiva ampliada que envolva de forma integrada e integradora diversas outras áreas como comunicação, telecomunicações, cultura, justiça, entre outras.

Vale, por fim, reafirmar que este dossiê é fruto da reflexão e da prática que foi realizada a muitas mãos e vozes nos grupos de pesquisa GEC e Comunic. Primamos pelo trabalho coletivo e colaborativo e a autoria nesses contextos, muitas vezes, é definida por uma linha muito tênue. Seria justo dizer que quando formalizamos em palavras o que discutimos nos contextos interativos do Projeto, podemos reconhecer a presença de todos. Mais do que a imagem do mosaico, do todo que reúne as várias partes individuais, uma melhor analogia para nosso trabalho seria o holograma, em que cada parte traz o todo em si. Não somos fragmentos que se reúnem, pois já estamos tão misturados que já nos identificamos uns nos outros. Somos fractais, não fragmentos.

Nossa proposta e aposta é que essas redes aqui pensadas, experimentadas e compartilhadas possam ser melhoradas, inspirando muitas outras tentativas. Assim, que possamos permanecer e penetrar, crescer e continuar. Para seguirmos juntos a partir daqui, oferecemos nossa "casa" coletiva para que possa ser um espaço para essa continuidade do diálogo: www.escolamundo.ufsc.br ou escolamundo.ufba.br.

\section{Referências}

ADORNO, Theodor; HORKHEIMER, Max. Dialética do esclarecimento: fragmentos filosóficos. Rio de Janeiro: Zahar, 1985.

ALBAGLI, Sarita; MACIEL, Maria Lucia; ABDO, Alexandre Hannud (Org.). Ciência Aberta, questões abertas. Brasília/Rio de Janeiro: IBICT e UNIRIO, 2015. Disponível em: http://livroaberto.ibict.br/handle/1/1060

BARTOLOMÉ PINA, Antonio. Comunicación y aprendizaje en la Sociedad del Conocimiento. Virtualidad, Educación y Ciencia - VEsC, año 2, n. 2. ISSN: 1853-6530, p. 9-46, 2011. Disponível em: http://revistas.unc.edu.ar/index.php/vesc/article/viewFile/332/331 Acesso em: 28 de Out. 2014. 
BENKLER, Yonkai. The wealth of networks: how social production transforms markets and freedom. Harvard Journal of Law \& Technology. v. 20, n. 1. New Haven, CT: Yale University Press, 2006.

BENKLER, Yonkai. La riqueza de las redes: cómo la producción social transforma los mercados y la libertad. Barcelona: Icaria Editorial, 2015.

BRASIL. Comitê Nacional de Educação em Direitos Humanos. Plano Nacional de Educação em Direitos Humanos. Brasília: Secretaria Especial de Direitos Humanos, Ministério da Educação, Ministério da Justiça, Unesco, 2009.

BONILLA, Maria Helena; PRETTO, Nelson De Luca. Movimentos colaborativos, tecnologias digitais e educação. Em Aberto, Brasília, v. 28, n. 94, p. 23-40, jul./dez. 2015.

DAYRELL, Juarez. A escola "faz" as juventudes? Reflexões em torno da socialização juvenil. Educ. Soc., v. 28, n. 100 - Especial, p. 1105-1128, Campinas, SP, out. 2007. Disponível em: $<$ http://www.cedes.unicamp.br> Acesso em 28 nov. 2007

ESPÍNDOLA, Marina Bazzo de. Integração de tecnologias de informação e comunicação no Ensino Superior: análise das experiências de professores das áreas de ciências e da saúde com o uso da Ferramenta Constructore. Rio de Janeiro/UFRJ/IBqM, 2010.

FEENBERG, Andrew. Transforming technology: a critical theory revisited. New York: Oxford University Press, 2002.

FORTUNATI, Leopoldina. Media between power and empowerment: can we resolve the dilemma?. The Information Society, 30: 169-183, 2014.

HIMANEN, Pekka. A ética dos hackers e o espírito da era da informação. Rio de Janeiro: Campus Editora, 2001.

KEEN, Andrew. The cult of the amateur: how today's internet is killing our culture. Nova York: Doubleday/ Currency. 2007

KELLNER, Douglas. Critical theory, marxism and modernity. Cambridge: Polity/John Hopkins University Press, 1989.

LAPA, Andrea Brandão; DE ESPÍNDOLA, Marina. B.. Desafios da formação de professores para a integração de TIC. In: Claudia Susie Camargo Rodrigues, Cláudia Maria Lima Werner e Tamara Tania Cohen Egler. (Org.). Educação, Tecnologia e Cidade: uma experiência interdisciplinar. 1ed.Rio de Janeiro: Letra Capital, 2019, v. 4, p. 79-95.

LAPA, A. B.; LACERDA, A. L. (Org.) . Formação de sujeitos em espaços sociais virtuais. 1. ed. Rio de Janeiro: Letra Capital, 2018. v. 1. 178p .

LEVY, Steven. Os heróis da revolução: como Steve Jobs, Steve Wosniak, Bill Gates, Mark Zuckenberg e outros mudaram para sempre nossas vidas. São Paulo: Évora, 2012.

MACHADO, Arlindo. Arte e mídia: aproximações e distinções. Galáxia, n. 4, 2002. p. 19-32. Disponível em:

http://revistas.pucsp.br/index.php/galaxia/article/view/1289/787.

NÓVOA, António. Nada será como antes: entrevista [novembro, 2014]. Revista Pátio Ensino Fundamental: o futuro da sala de aula, n. 72. Nov. 2014. Disponível em:

http://www.grupoa.com.br/revista-patio/artigo/10938/nada-sera-como-antes.aspx Acesso em: 26 jan. 2015. 
Organizadoras

Andréa Brandão Lapa (UFSC)

Marina Bazzo de Espíndola (UFSC)

Nelson de Luca Pretto (UFBA)
PRETTO, Nelson De Luca. Educações, culturas e hackers: escritos e reflexões. Salvador, Bahia: Edufba, 2017. .978-85-232-1654-2.

PRETTO, Nelson De Luca. O desafio de educar na era digital: educações. Revista Portuguesa de Educação. v. 24, n. ， 2011, p. 95-118. Disponível em: http://revistas.rcaap.pt/rpe/article/view/3042/2459

PRETTO, Nelson. "Redes colaborativas, ética hacker e educação". Belo Horizonte: UFMG. Educação em Revista, 26: 305-316, 2010.

PRETTO, Nelson De Luca; PINTO, Cláudio da Costa. Tecnologias e novas educações. Revista Brasileira de Educação. v. 11 n. 31 jan./abr. 2006. p.19-30. Disponível em: http://cev.org.br/biblioteca/tecnologias-novas-educacoes

QUARTIERO, Elisa; BONILlA, Maria Helena Silveira; FANTIM, Monica. Projeto UCA: entusiasmos e desencantos de uma política pública. Salvador, Ba: EDUFBA, 2015. .97885-232-1396-1.

RHEINGOLD, Howard. The virtual community. Reading (MA): Addison-Wesley, 1993.

SHIRKY, Clay. A Cultura da participação: criatividade e generosidade no mundo conectado. Trad. Celina Portocarrero. Rio de Janeiro: Zahar, 2011.

SODRÉ, Muniz. Reinventando a educação: diversidade, descolonização e redes. 2. ed. Petrópolis, RJ: Vozes, 2012.

TURKLE, Sherry. Alone together. Nova York: Basic Books, 2011. 